\title{
МАТЕМАТИЧЕСКИЕ ПРЕДПОСЫЛКИ КОНСТРУИРОВАНИЯ ФРОНТАЛЬНОЙ ГРУППЫ ЗУБОВ ПРИ ПРОГЕНИЧЕСКОМ СООТНОШЕНИИ БЕЗЗУБЫХ ЧЕЛЮСТЕЙ
}

\section{MATHEMATICAL PREREQUISITES FOR THE DESIGN OF THE FRONTAL GROUP OF TEETH WITH A PROGENIC RATIO OF THE EDENTULOUS JAWS}

D. Aksyonov Yu. Mayboroda I. Aksenov

Summary. Aim. Improving the efficiency of designing anterior segments of artificial teeth with a progenic ratio of jaws.

Methods. With the help of the designed measuring device, the degree of divergence of the sagittal fissure of the frontal segments of the edentulous jaws was determined, on the basis of which the variants of the level of the ratio of the interalveolar lines were calculated.

Results. On the basis of mathematical calculations, taking into account the anthropometric data of digital measurements of the alveolar ridges of the frontal segments of the edentulous jaws, the principles of designing artificial dentition with a progenic ratio of the alveolar processes are considered. The digital values of the mean square deviation of the interalveolar lines at different levels of the sagittal fissure were obtained. Three main variations in the progenic ratio of the frontal segments, the shape of their dental arches and the angles of inclination in relation to the general interalveolar lines are reflected.

Conclusions. On the basis of mathematical calculations, the optimal methods for the placement of artificial teeth in complete removable dentures have been developed with various degrees of progenic ratio of the frontal segments of the edentulous jaws.

Keywords: mathematical model, edentulous jaws, alveolar processes of edentulous jaws, progeny.

\author{
Аксёнов Даниил Игоревич \\ Аспирант, Ставропольский Государственный \\ Медицинский Университет \\ Майборода Юрий Николаевич \\ Дочент, Ставропольский Государственный \\ Медицинский Университет \\ Аксёнов Игорь Николаевич \\ К.м.н., ассистент, Ставропольский
}

Государственный Медицинский Университет

p.ghost@rambler.ru

Аннотация. Цель: Повышение эффективности конструирования фронтальных сегментов искусственных зубов при прогеническом соотношении челюстей.

Методы. С помощью сконструированного измерительного устройства, определили степень расхождения сагиттальной щели фронтальных сегментов беззубых челюстей, на основе которых вычислялись варианты уровня соотношения межальвеолярных линий.

Результаты. На основе математических расчётов с учетом антропометрических данных цифровых измерений альвеолярных гребней фронтальных сегментов беззубых челюстей, рассматриваются принципы конструирования искусственных зубных рядов при прогеническом соотношении альвеолярных отростков. Получены цифровые значения среднеквадратического отклонения межальвеолярных линий при различном уровне сагиттальной щели. Отражены три основных вариаций прогенического соотношения, фронтальных сегментов, формы их зубных дуг и углы наклона по отношению к общим межальвеолярным линиям.

Выводы. На основе математических расчётов, разработаны оптимальные способы расстановки искусственных зубов в полных съёмных протезах при различных степенях прогенического соотношения фронтального участка беззубых челюстей.

Ключевые слова: математическая модель, беззубые челюсти, альвеолярные отростки беззубых челюстей, прогения.

Особенности атрофических изменений альвеолярных отростков на нижней челюсти отражаются на степени фиксации и стабилизации протезов, а также на уровень жевательной эффективности, фонетики и эстетики $[2,7$, 18]. Полное отсутствие зубов встречается у $22-46 \%$ пациентов, обратившихся за ортопедической помощью, среди которых прогеническое соотношение челюстей различного уровня размеров сагиттальной щели пред- 
ставляет особые трудности протезирования [13, 14, 18], особенно у лиц пожилого возраста. Последнее обусловлено прогрессивными атрофическими изменениями тканевых образований протезного ложа беззубых нижних челюстей, на фоне частой общесоматической патологии их организма в целом $[3,7,8]$.

\section{Аитературный обзор}

Если приблизительное соотношение челюстей у беззубых пациентов хотя и возможно установить вне зависимости от потери зубов и связанных с этим вторичных изменений, то анализ соотношения моделей в артикуляторе не всегда позволяют окончательно определить соотношение челюстей и решение клинических вариантов к таким ситуациям является беспредметным. По данным литературы прогенические варианты альвеолярных отростков беззубых челюстей может быть либо следствием истинной скелетной формы мезиальной окклюзии, либо являются результатом резорбции кости в разных плоскостях, а также иметь комбинированные варианты [3, 20]. И поэтому часто возникают определённые сложности подобрать оптимальный вариант расстановки зубов для конкретного пациента [10]. В таких случаях используют дополнительный анализ телерентгенограммы, традиционно применяющийся в ортодонтии [17]. Возможность длительного использования некачественных протезов свидетельствует о значительном адаптационном потенциале челюстно-лицевой системы - жевательных мышц. Смещение мыщелково мезиальной части связано с адаптацией ВНЧС к вынужденной прогении $[16,19]$.

В клинике ортопедической стоматологии у беззубых больных различают две основные формы прогенического соотношения челюстей - подлинная прогения и прогения обусловленная мезиальным смещением альвеолярных отростков на фоне ортогнатического прикуса до потери зубов за счёт их неадекватной резорбции $[2,21]$. На фоне иррационального наклона искусственных зубов во фронтальном участке формируется парафункциональное состояние вследствие уменьшения ротовой щели для языка, который способствует ухудшению стабилизации протезов во время функции жевания, глотания и разговора, что затрудняет адаптацию больных к протезам [8, 15]. Кроме того, из-за более мезиального расположения верхних фронтальных зубов по отношению к нижним изменяется функция губ, под давлением которых происходит смещение протезов в дистальном направлении.

Имеющиеся способы конструирования фронтальных сегментов зубных рядов на фоне прогенических вариантов сагиттальной щели предусматривают расстановку зубов в прогении с созданием контакта меж- ду зубами, или же постановку зубов, имитирующие расположение естественных зубов у пациентов до их элиминации [7, 10, 13, 14, 21]. Существующие методики конструирования зубных рядов при прогеническом соотношении фронтальных сегментов зубных рядов несут в своей основе элементы погрешностей, так как в них не приводятся параметры цифровых величин, на основе которых рассчитываются углы наклона искусственных зубов по отношению к вершинам альвеолярных гребней. Таким образом, многочисленные и разнообразные предлагаемые способы клинических и лабораторных этапов конструирования зубных рядов констатируют о необходимости решения проблемы, одним из моментов которых является до сих пор открытым вопрос принципам конструирования зубных рядов при мезиальном соотношении челюстей на основе метода математических расчётов.

Целью исследования являлось разработка оптимального способа конструирования искусственных зубных рядов при прогенических вариантах соотношения альвеолярных отростков с учётом математического анализа гипсовых моделей $[4,9]$ беззубых челюстей. Достижение указанной цели диктовалось необходимостью определения расстояния сагитальной щели между альвеолярными гребнями фронтальных сегментов в межальвеолярном пространстве для определения единой межальвеолярной дуги и углах их расхождения.

\section{Материалы и метолы}

Основой математических расчётов послужили 79 беззубых пациентов с различным уровнем расстояния сагиттальной щели при прогеническом соотношении альвеолярных отростков. Были установлены общая межальвеолярная дуга и углы наклона межальвеолярных линий по отношению к сагиттальной плоскости, которые осуществлялись на базе 79 пар гипсовых моделей беззубых челюстей. Измерение расстояния осуществлялось с помощью сконструированного измерительного устройства [1]. Конструкция представляет собой комплект подвижных и неподвижных соединений, основу которых составляют две линейки с боковыми ползунками с вертикальными стержнями и миллиметровая сетка с двумя взаимно перпендикулярными цифровыми параметрами в миллиметрах. В каждом случае определяли расстояние между центральными и боковыми резцами, и клыками с левой и правой сторон.

\section{Результаты исслеАования}

В данной статье приводятся первые три варианта математических расчётов с различным уровнем соотношения сагиттальной щели альвеолярных отростков 
Таблица 1. Цифровые данные расстояния между верхними и нижними альвеолярными гребнями фронтальных сегментов беззубых челюстей (мм)

\begin{tabular}{|c|c|c|c|c|c|c|}
\hline \multirow{2}{*}{ Группы } & \multicolumn{6}{|c|}{ Зубы } \\
\hline & 13 & 12 & 11 & 21 & 22 & 23 \\
\hline Группа I, n=19 & 0,57 & 0,45 & 0,35 & 0,73 & 0,90 & 0,90 \\
\hline Группа II, n=46 & 3,13 & 3,02 & 1,81 & 1,98 & 2,96 & 3,45 \\
\hline Группа III, n=14 & 7,5 & 6,5 & 6,5 & 6,0 & 6,5 & 6,5 \\
\hline \multicolumn{4}{|l|}{ Правые } & \multicolumn{3}{|c|}{ Левые } \\
\hline
\end{tabular}

Где n- количество наблюдений (пациенты)

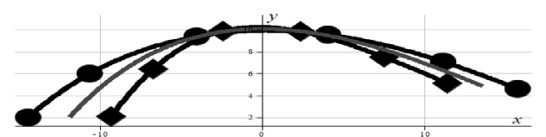

a)

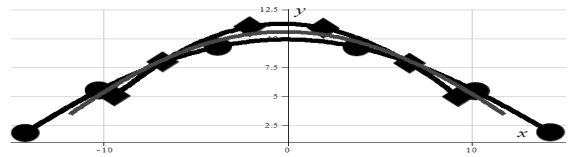

б)

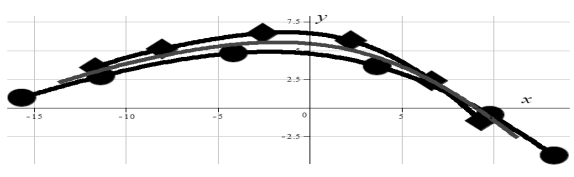

B)

Рис. 1. Средне межавльвеолярные дуги фронтальных сегментов для верхней и нижней челюстей

а) Прогения слабо выраженная с обеих сторон

б) Прогения выраженная средне с обеих сторон

в) Прогения резко выраженна по всей дуге

фронтальных сегментов беззубых челюстей, позволяющие производить оптимальную методику расстановки искусственных зубов в артикуляторе.

Исходя из задачи исследования расчёты для построения средней линии между дугами верхней и нижней челюстей и вычисления их углов между соответствующими фронтальными зубами осуществляли на основе цифровых данных. Для решения этой задачи, а именно определения величины углов между дугами в соответствующей точке топографического расположения каждого из фронтальных зубов рассчитывают систему координат и абсцисс с последующим определением по формуле Лангранжа [6] форм и дуг альвеолярных гребней челюстей в трёхмерной системе координат. При формировании средней межальвеолярной дуги применяли те же методы математических расчётов, что и при построении дуг для фронтальных сегментов верхней и нижней челюстей. Для этого применяли показатели высоты и ширины коронок постоянных зубов (В.Д. Устименко, 1973) [11] и цифровые параметры сагитальной щели между фронтальными сегментами обеих челюстей (табл. 1).

Как видно из таблицы размеры сагиттальной щели во фронтальных сегментах обеих челюстей трёх групп пациентов отражают вариабельный разброс цифровых параметров и формы зубных дуг характеризуются большой разновидностью. На основе цифровых данных расхождения фронтальных участков альвеолярных гребней между обеими челюстями в данной статье мы приводим три первых наиболее часто встречающихся варианта прогенического соотношения челюстей, которые схематически отражены на рисунке 1.

Для определения величины углов для каждой пары верхних и нижних адекватных зубов соизмеряли на основе прямоугольного треугольника (рис. 2), образованного прямой, соединяющей верхний и нижний зубы (на рис. 2 - гипотенуза), прямой $\operatorname{Str}_{i}$ (на рис. 2 - нижний катет), и прямой, соединяющей верхний зуб с его проекцией на $\operatorname{Str}_{i}$ (на рис. 2 - боковой катет):

Основными углами будут углы $\alpha_{i}$, образованные линиями, пересекающие аналогичные верхние и нижние фронтальные зубы и линиями, соединяющими нижние зубы с началом координат. По определению тангенса [6], вычисляют углы для каждой пары соответствующих верхнего и нижнего зубов $\alpha_{i}$ по формуле (рис. 3).

Исходя из данных, приводимых в таблице 2, углы расхождения для каждой пары артикулирующих зубов 
Таблица 2. Градусные меры межальвеолярных углов фронтальных сегментов беззубых челюстей

\begin{tabular}{|l|l|l|l|l|l|l|}
\hline Название зубов & 13 & 12 & 11 & 21 & 22 & 23 \\
\hline Группа I, $\mathrm{n}=19$ & 1040 & $99 \circ$ & $91 \circ$ & $90 \circ$ & $100 \circ$ & $107 \circ$ \\
\hline Группа II, $\mathrm{n}=46$ & $100 \circ$ & $93 \circ$ & $86^{\circ}$ & $86^{\circ}$ & $93 \circ$ & $99 \circ$ \\
\hline Группа III, $\mathrm{n}=14$ & $91 \circ$ & $79 \circ$ & $75 \circ$ & $74 \circ$ & $78 \circ$ & $93 \circ$ \\
\hline
\end{tabular}

где $\mathrm{n}$ — количество наблюдений (пациенты)

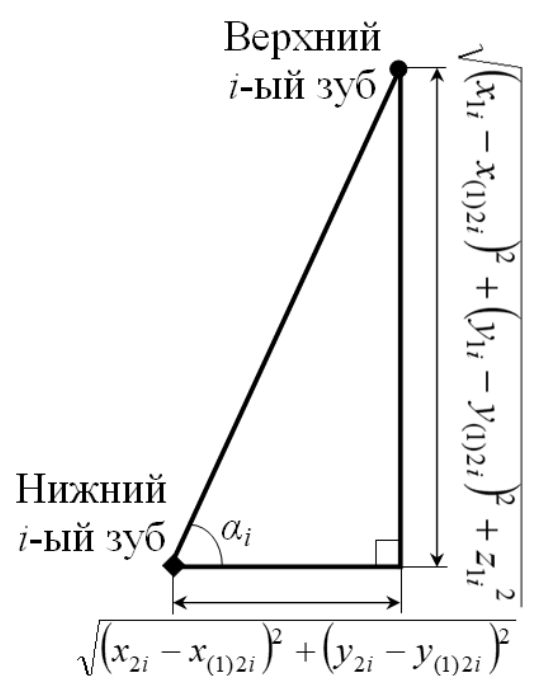

Рис. 2. Вычисление угла

$$
\alpha_{i}=\left\{\begin{array}{c}
\pi-\operatorname{arctg}\left(\sqrt{\frac{\left(x_{1 i}-x_{(1) 2 i}\right)^{2}+\left(y_{1 i}-y_{(1) 2 i}\right)^{2}+z_{1 i}^{2}}{\left(x_{2 i}-x_{(1) 2 i}\right)^{2}+\left(y_{2 i}-y_{(1) 2 i}\right)^{2}}}\right), \text { если } x_{(1) 2 i}^{2}+y_{(1) 2 i}^{2}>x_{2 i}^{2}+y_{2 i}^{2}, \\
\operatorname{arctg}\left(\sqrt{\frac{\left(x_{1 i}-x_{(1) 2 i}\right)^{2}+\left(y_{1 i}-y_{(1) 2 i}\right)^{2}+z_{1 i}{ }^{2}}{\left(x_{2 i}-x_{(1) 2 i}\right)^{2}+\left(y_{2 i}-y_{(1) 2 i}\right)^{2}}}\right), \text { иначе, } \\
\text { где } \mathrm{i}=1.6
\end{array}\right.
$$

Рис. 3

(клыки, резцы) имели свои вариации. При этом отмечается значительное расхождение углов альвеолярных гребней в третьей группе пациентов при прогеническом соотношении фронтального сегмента по всей дуге.

Расстановка искусственных зубов при первых двух вариантах, когда сагиттальная щель имеет незначительный диапазон расхождения межчелюстных соотношений, производится в зависимости от величины углов. На основании цифровых расчётов межальвеолярной щели конструирование фронтальных зубов при первом варианте осуществляют в ортогнатическом соотношении с некоторым учётом смещения отдельных зубов по отношению к конфигурации альвеолярных гребней. При втором варианте в пределах расхождения между альвеолярными дугами не более 3,0 мм и углов в интервале 86-100\% конструируют форму расстановки зубов в прямом или прогеническом варианте при плотном контакте вестибулярный поверхности верхних зубов с язычной поверхностью нижних искусственных зубов, 
также учитывая уровень наклона углов по отношению к альвеолярным гребням.

При слишком выраженном прогеническом соотношении фронтальных отделов беззубых челюстей (от 6,5 до 7,5 мм) центральные и боковые резцы расставляют в прогеническом соотношении с учётом степени наклона срединной межальвеолярной линии без контакта между фронтальными зубами или же в минимальном контакте области клыков, учитывая степень расхождения углов наклона вершин альвеолярных гребней.

\section{Зак^ючение}

Представленная на основе математических расчётов методика оптимального конструирования зубных рядов, позволяет учитывать уровень асимметрии, конфигурации и наклона межальвеолярных линий правой и левой сторон фронтальных сегментов и, этим самым, проводить индивидуализированную постановку зубов с учётом уровня углов наклона альвеолярных гребней по отношению к протетической плоскости в межрамочном пространстве артикулятора.

\section{ЛИТЕРАТУРА}

1. Аксёнов Д.И., Майборода Ю.Н. Антропометрическое измерительное устройство. Решение о выдаче патента на изобретение, заявка № 2020125944/14 (045353) от 17.12.2020.

2. Воронов А.П., Лебеденко И.Ю., Воронов И.А. Ортопедическое лечение больных с полным отсутствием зубов. М., 2006. 316 с.

3. Гиоева Ю.А., Персин Л.С. Мезиальная окклюзия зубных рядов. М.: Медицина, 2008. 192 с.

4. Гришечкин С.Д., Саферян К.Г., Гришечкин М.С., Ижнина Е.В. Грамотная постановка искусственных зубов с учётом анализа гипсовых моделей беззубых челюстей // Клиническая стоматология. 2014. № 3 (71). С. 50-52.

5. Гельфанд И.М., Львовский С.М., Тоом А.Л. Тригонометрия. М.: МЦНМ0, 2002. 199 с.

6. Демидович Б.П., Марон И.А., Шувалова Э.З. Численные методы анализа. М.: Наука, 1967. 368 с.

7. Загорский В.А. Протезирование при полной адентии. М.: Медицина, 2008. 375 с.

8. К Климашин Ю.И. К вопросу о фиксации полных съёмных протезов на нижней челюсти при протезировании в особо сложных клинических условиях // Стоматология. 2012. № 2. С. 51-53.

9. Колесников Л.Л., Аникин Ю.М. Математический анализ строения элементов зубочелюстной системы // Морфология. 1997. № 2. С. 98-102.

10. Крунич Н., Костич М., Янушевич П., Петрович Д., Костич И., Петрович М., Игич М. Протезирование больного с соотношениями челюстей по III классу // Стоматология. 2014. № 1. С. 46-49.

11. Персин Л.С. Ортодонтия. Диагностика и лечение зубочелюстных аномалий. М.: Медицина, 2004. С. 70.

12. Саввиди К.Г. Методика повторного протезирования на беззубой нижней челюсти у пациентов пожилого и старческого возраста с неблагоприятными клиническими условиями протезного ложа // Институт стоматологии. 2008. № 4. С. 34-35.

13. Садыков М.И., Тлустенко В.П., Комлев С.С., Тлустенко В.С., Шелеметев С.В. Совершенствование ортопедического лечения больных с полным отсутствием зубов // Институт стоматологии. 2008. № 4. С. 54-55.

14. Тлустенко В.С. Ортопедическое лечение больных при выраженном прогеническом соотношении беззубых челюстей полными съёмными протезами // Аспирантский вестник Поволжья. 2008. № 3-4. С. 168-172.

15. Шарапова А.И. Язык как проблема в съёмном протезировании беззубой нижней челюсти // 7-я международная конференция челюстно-лицевых хирургов и стоматологов: Сб. материалов. СПб., 2002. С. 164.

16. Amorium V.C.P., laguna D.V., de Paula Eduardo J.V., Zanetti A.L. Analysis of the condyle/fossa relationship before and after prosthetic rehabilitation with maxillary complete denture and mandibular removable partial denture // Journal of Prosthetic Dentistry. 2003. № 89. Pp. 508-514.

17. Ciftci Y., Kocadereli I., Canay S., Senyilmaz P. Cephalometric Evalution of Maxillo mandibular Relationship in Patients Wearing Complete dentures: a pilot study // The Angle Orthodontist. 2005. № 75. Pp. 821-825.

18. Cuman Y., Musnata C., Nanninin М. Изготовление полносъёмных протезов по методу Славичека. М: Медицинская пресса, 2009. 138 c.

19. Leki K., Nakagawa K., Marukawa K., Yomamoto E., Takenchi N. Stress change of temoromandibular joint in mandibular prognatism subjects with asymmetry after orthognothic surgery // European Journal of Orthodontics. 2010. № 32. Pp. 522-529.

20. Okuma K., Hihazo S., Hayakawa J. Occlusal pressure patent analisis of complete dentures for evaluation of occlusial adjustment // Journal of Medical and Dental Sciences. 2004. Vol. 51. No 4. Pp. 197-203.

21. Wisser W. Rationeles Fertiqunqsverfahren fur die Totalprothetik // Das Dental Labor. 2003. Vol. 51. № 3. Pp. 439-445.

( ) Аксёнов Даниил Игоревич, Майборода Юрий Николаевич, Аксёнов Игорь Николаевич ( p.ghost@rambler.ru ). Журнал «Современная наука: актуальные проблемы теории и практики» 